\title{
CARACTERÍSTICAS AMBIENTAIS DAS COMUNIDADES DE BAIACU E DE CACHOEIRA NA BAÍA DE TODOS OS SANTOS - BAHIA- BRASIL
}

\author{
J. M. TAVARES* ${ }^{*}$ P. M. A. SOUZA \\ Instituto Federal de Educação, Ciência e Tecnologia da Bahia \\ jmtavares@ifba.edu.br*
}

Artigo submetido em julho/2015 e aceito em setembro/2016

DOI: $10.15628 /$ holos.2016.4664

\section{RESUMO}

Esta pesquisa aborda algumas características do meio ambiente e avalia o estado de degradação das regiões de Cachoeira e de Baiacu na BTS. Foram efetuados registros de imagens, das condições de saneamento e socioambientais, como também foram realizados testes laboratoriais na água de consumo. Os resultados mostraram inexistência de um saneamento adequado e de uma coleta não seletiva em toda a extensão das comunidades, descartes de resíduos no manguezal, instalações hidráulicas ineficientes, dentre outras. A água de consumo ingerida pelas comunidades, possivelmente, não se encontra em conformidade com os parâmetros de potabilidade, já que os resultados mostraram a presença de coliformes totais em $40 \%$ das amostras e de teores de cloro menores do que os valores indicados pelos padrões. Por causa desta realidade são necessárias limpezas periódicas dos reservatórios, manutenção das instalações hidráulicas, monitoramento contínuo da qualidade da água, como também a conscientização de as pessoas e dos setores públicos. Desta forma, pode-se garantir a qualidade de vida das comunidades e assim, preservar o meio ambiente de Cachoeira e de Baiacu na Baía de Todos os Santos na Bahia.

PALAVRAS-CHAVE: potabilidade, meio ambiente, água

\section{ENVIRONMENTAL ANALYSIS BAIACU AND CACHOEIRA COMMUNITY IN BAÍA DE TODOS OS SANTOS - BAHIA- BRAZIL}

\begin{abstract}
This research discusses some features of the environment and assesses the state of degradation of the regions Waterfall and Blowfish in BTS. Images records were made, the sanitation and environmental, as were also conducted laboratory tests on water consumption. The results showed lack of adequate sanitation and a collection nonselective to the fullest extent of communities, waste disposal in the mangrove, inefficient hydraulic installations, among others. The water consumption consumed by communities, possibly, not in
\end{abstract}

accordance with the potability parameters, as the results showed the presence of coliforms in $40 \%$ of samples and lower chlorine content than the values set by standards. Because of this reality, periodic cleaning of reservoirs, maintenance of hydraulic systems, continuous monitoring of water quality, as well as the awareness of the people and public sectors. In this way, we can ensure the quality of life of communities and thus preserve the environment Cachoeira and Baiacu in the Baía de Todos os Santos in Bahia - Brazil.

KEYWORDS: Potability, environment, water. 


\section{INTRODUÇÃO}

A Baía de Todos os Santos (BTS) é uma das maiores baías do Brasil, abrigando dezenas de ilhas, sendo a llha de Itaparica a maior delas. A llha de Itaparica abriga os municípios de Vera Cruz e de Itaparica, dentre outros. Rica em recursos naturais, paisagens deslumbrantes e diversidade cultural e cênica, por isso a llha tem atraído turistas e moradores, estes notadamente compostos de pescadores. A ocupação desordenada e o uso indiscriminado dos recursos naturais têm levado a um cenário de degradação de o ambiente insular, incluindo contaminação de mananciais aquíferos e das praias e a descaracterização da vegetação pela expansão desordenada dos condomínios.

A Vila de pescadores de Baiacu é uma comunidade pertencente ao município de Vera Cruz, situado na Ilha de Itaparica. Distante de Salvador $43 \mathrm{~km}$, está localizada na contra- costa da Ilha. A comunidade que ali se instalou é predominantemente negra, composta por marisqueiras e por pescadores artesanais, que buscam na pesca de peixes e de mariscos sua subsistência e única fonte de renda assim, em geral uma população e baixa renda. Até meados século 20, o povoado era conhecido por sua produção pesqueira, condição que foi se modificando ao longo do tempo. Embora próximo à comunidade, o acesso ao povoado é difícil, sendo uma das comunidades mais isoladas da ilha. Foi escolhida a comunidade de Baiacu, devido aos sérios problemas constatados, como a devastação do manguezal, redução dos mariscos e de peixes; empobrecimento das pessoas da comunidade; exploração de mão de obra, dentre outras. Um fato muito importante foi à interdição do aterro sanitário pela Secretaria de Meio Ambiente do Estado, pelo qual foi transformado em lixão e por isso, enfrenta sérios problemas com a gestão e gerenciamento dos resíduos sólidos. Tanto os resíduos do Município de Vera Cruz quanto os de Itaparica são depositados no Lixão no Bairro de Baiacu, o qual pertence ao Município de Vera Cruz (Hatje, Andrade, 2009; Costa, 2006).

A Cidade de Cachoeira está situada no Recôncavo Baiano e margeia o Rio Paraguaçu, sendo seu último ponto navegável. A paisagem de algumas cidades do Recôncavo mudou ao longo do tempo, hoje Cachoeira comporta uma intensa atividade turística, abriga um dos campi da UFRB, fazendo com que estudantes de variados locais do país, desloquem-se para esta pequena cidade para estudar. Nesta comunidade, os problemas relacionados à falta de gestão adequada dos resíduos sólidos urbanos estão cada vez mais perceptíveis, devido aos hábitos da sociedade voltados para o consumo de bens e produtos, que provoca um aumento relevante na quantidade e qualidade de lixo produzido.

O rio Paraguaçu é o maior rio genuinamente baiano, pois seu curso vem desde a foz na Baía de Todos os Santos até a cidade de Cachoeira. Este rio é responsável pelo abastecimento de água da cidade em destaque (EMBASA, 2011; Rosa et al. 2001).

Sabe-se que o sistema de limpeza urbana assim como os de tratamento de água é fundamental para a sociedade (Rios, 2008; Francis, 2015). Observa-se na Figura 01, que a quantidade de resíduos revela a gravidade da situação em que se encontra o trecho do curso de água que banha a cidade. Excessos de lixo e de resíduos poderão contaminar a fonte de água distribuída para a população, assim como em toda a região. Pode-se dizer que a origem da poluição presente na comunidade pode estar relacionada pela disposição inadequada do lixo doméstico a 
céu aberto, exploração mineral excessiva, desmatamentos e pelas atividades agropastoris (Rios, 2008). Estas atividades desencadeiam processos erosivos, assoreamento das calhas dos rios e o lançamento de praguicidas nos solos. Foi verificado descuido em relação ao saneamento básico em algumas cidades situadas próximas às margens do rio Paraguaçu, assim como a geração de resíduos sólidos de maneira desordenada e a disposição inadequada pode contribui para impactos negativos na região.

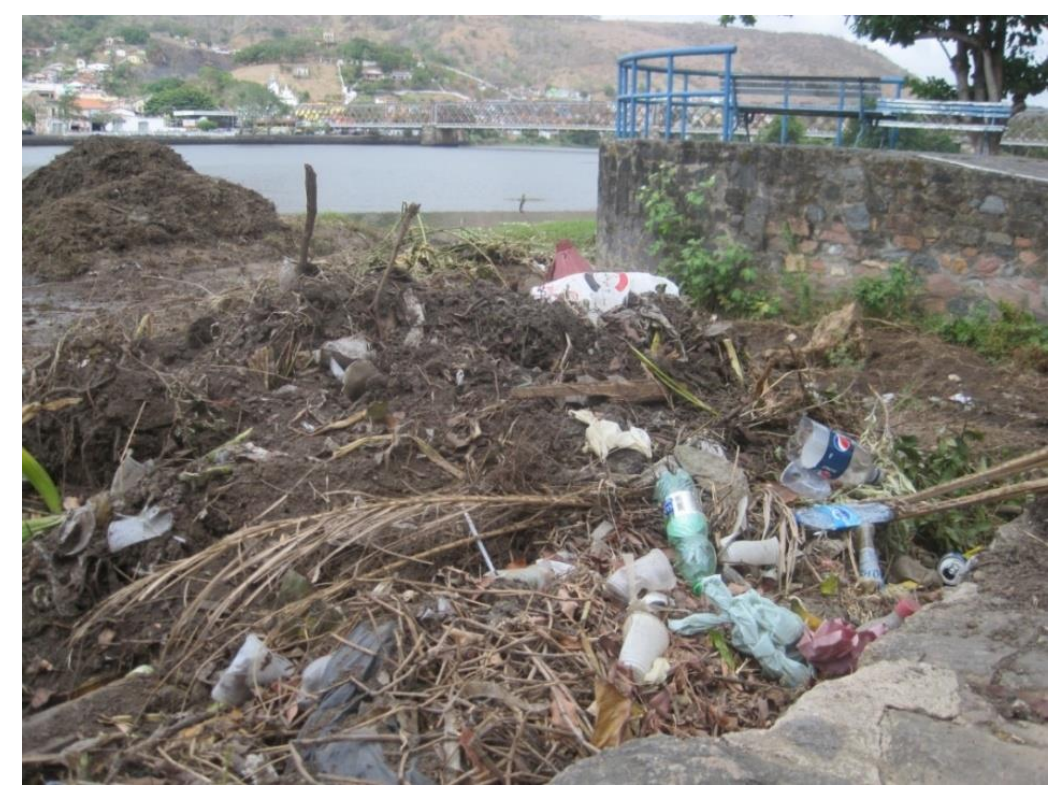

Figura 1: Resíduos e entulhos as margens do Rio Paraguaçu, 2013.

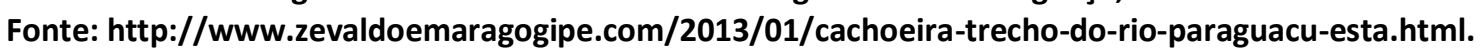

O rio Paraguaçu sofre problemas ambientais que começam desde o desmatamento registrado nas cabeceiras dos seus afluentes e vão até o descaso dos habitantes das cidades atravessadas por ele, que jogam lixo e entulhos, provocando a poluição e o assoreamento do leito. Recentemente foi efetuada uma operação de limpeza na cidade de Cachoeira e em duas semanas foram recolhidas 800 toneladas de lixo e entulho das margens do rio. Na região do baixo e médio curso do rio Paraguaçu ocorre também o lançamento de efluentes das indústrias oriundos de Feira de Santana e do Centro Industrial de Subaé - CISTomba. Esses fatos poderão interferir na qualidade da água já que esta é proveniente do rio Paraguaçu, que está submetido a diversos tipos de contaminação (Embasa, 2011). Na avaliação da qualidade das águas realizada na bacia hidrográfica do rio Paraguaçu e seus afluentes no ano 2001, o que inclui a região avaliada, notou-se que o despejo de dejetos orgânicos (esgotos domésticos) comprometeu as águas utilizadas pelo rio, o que ocasionou resultados acima dos valores recomendados pelos padrões.

Cenários como este tem despertado o interesse sobre acumulação e toxicidade de contaminantes químicos e biológicos, como conseqüência das exposições ocupacionais e ambientais, ou dos distúrbios causados por estes elementos, induzidos por situações especiais de doença. O consumo de água de qualidade duvidosa pode reduzir o tempo de vida do ser humano, já que os contaminantes, uma vez absorvidos pelo organismo, não são completamente eliminados, provocando alterações metabólicas indesejáveis (Francis, 2015; Marcelo, 2010). Outros fatos relevantes que acontecem na região é a destruição dos mangues e das matas ciliares, afetando diretamente a qualidade de vida das pessoas que habitam essa região. 
Dada a importância de Cachoeira e ao potencial pesqueiro da localidade de Baiacu, esta pesquisa pretende avaliar as características ambientais atuais destas comunidades, bem como analisar as propriedades físico-químicas e biológicas da água consumida.

\section{METODOLOGIA}

A metodologia utilizada neste trabalho visa avaliar o estado ambiental da comunidade de Cachoeira e de Baiacu na Baía de Todos os Santos, assim como determinar as características físicoquímicas e bacteriológicas da água de consumo. Para a concretização dos objetivos almejados, foram executadas as seguintes etapas: (i) Levantamento bibliográfico, (ii) Pesquisa de campo com levantamento fotográfico e registro de imagens acerca do estado ambiental das comunidades; (iii) Estudos acerca do saneamento básico e o tratamento de água; (iv) Seleção dos pontos de amostragens; (v) Coleta de amostras de água de consumo; (vi) Determinação das propriedades físico-químicas como: turbidez, $\mathrm{pH}$,dureza, sulfeto, cor aparente; nitrato, nitrito, cloro, amônia e análise microbiológica; (vii) Tratamento químico das amostras e determinação analítica dos metais e (viii) Tratamento de dados para facilitar a interpretação e sintetização dos resultados, associando-os à finalidade da pesquisa.

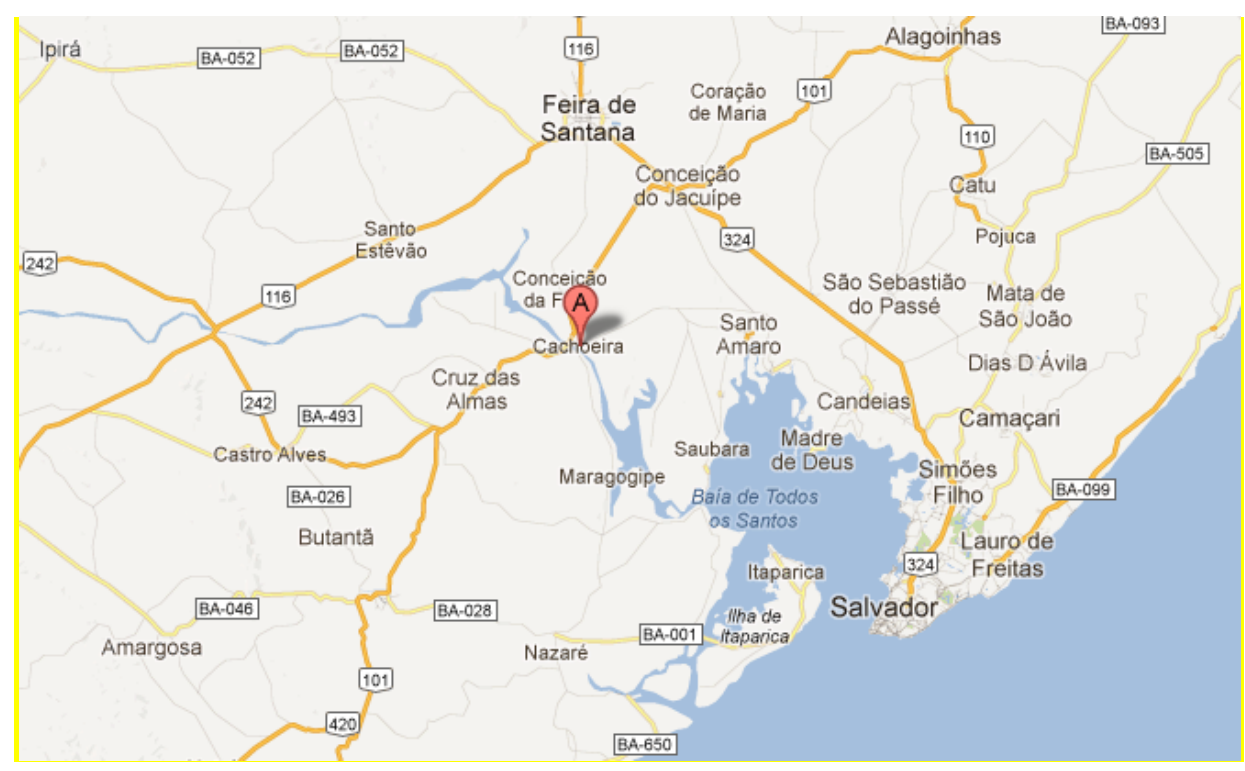

Figura 2 - Localização da Ilha de Itaparica e de Cachoeira na BTS. Fonte: https://google.com.br/maps.

Foi realizada uma observação prévia de 10 pontos estratégicos na localidade de Baiacu e de Cachoeira, tendo como prioridade pontos com maior contingente populacional. Foram coletadas amostras de água de poços cartesianos (quatro primeiros pontos amostrais) e de consumo diretamente da torneira residencial. Foi coletado água de poço, pois muitos dos moradores a utilizam para abastecer seus reservatórios. Na segunda etapa foram feitos os registros fotográficos dos pontos selecionados. O armazenamento das amostras de água foi feito em garrafas PET de $500 \mathrm{~mL}$ previamente descontaminadas; sendo que as garrafas foram etiquetadas e mantidas refrigeradas.

Os procedimentos de descontaminação dos materiais foram efetuados no Laboratório de Pesquisa do Departamento de Química do IFBA. Todas as vidrarias permaneceram por 10 minutos em um banho ultrassônico, sendo que os materiais foram lavados com detergente neutro (Extran) 
e o enxágüe foi realizado com água ultrapura. O detergente utilizado foi neutro e isento de fosfato para garantir a limpeza total. Em seguida, os materiais utilizados para determinar os teores de metais foram lavados com ácido nítrico $1 \%(\mathrm{v} / \mathrm{v})$ e imersos durante o tempo de 24 horas e ao término do procedimento de lavagem, os materiais foram também enxaguados com água destilada e com água ultrapura. Foram coletadas 10 amostras de água de consumo e realizadas as análises laboratoriais quanto à presença de coliformes totais, turbidez, $\mathrm{pH}$, dureza, sulfeto, cor aparente; nitrato, nitrito, cloro e amônia em replicatas. Estes testes serviram para avaliar alguns aspectos físico-químicos da água para o consumo humano e verificar se estão de acordo com os padrões de potabilidade propostos em legislação vigente, que credibilizam a qualidade da água.

Os testes físico-químicos foram realizados no laboratório de pesquisa do Departamento de Química do IFBA (Campus Salvador), segundo a metodologia padrão (APHA, 2005) para cada teste, como DPD (cloro); sulfeto (azul de metileno), dentre outros. As análises microbiológicas foram realizadas em laboratório certificado através do método dos substratos enzimáticos (APHA, 2005; LABTAN, 2008).

A determinação de cloro residual ou livre (DPD) nas amostras ocorreu com a adição da amina DPD (N,N-dietil-p-fenilenediamina), método este aprovado pelo EPA Método Padrão 4500Cl G (2). Na determinação de dureza total foi utilizado o método da Titulometria de Complexação, utilizando o negro E.T. e titulação com EDTA 0,01 M. Foi utilizado o método colorimétrico do azul de metileno para a determinação do sulfeto e na determinação de amônia foi aplicado o método do Azul de Indofenol.

\section{RESULTADOS E DISCUSSÕES}

No que se refere à avaliação do estado ambiental da comunidade de Baiacu e de Cachoeira na Baía de Todos os Santos, os estudos mostraram sérios problemas, tais como: devastação do manguezal, falta de saneamento básico, já que os dejetos residenciais são lançados no esgoto sem tratamento e, conseqüente para a maré; descarte aleatório de resíduos sólidos (em forma de embalagens que acondicionam alimentos e bebidas) principalmente latas, plásticos, vidros, em terreno baldio, nas praias e em pontos turístico é uma realidade, já que inexiste coleta seletiva; lançamento de óleos, tintas e a presença de um lixão (Figura 2).

Foi verificado que o lixão surgiu como conseqüência do abandono do aterro sanitário existente, que enfrenta sérios problemas em relação à gestão e ao gerenciamento dos resíduos sólidos. Tanto os resíduos do município de Vera Cruz quanto os de Itaparica são depositados no Lixão do Bairro de Baiacu, que pertence ao município de Vera Cruz. O aterro é considerado inadequado pela CETESB e o órgão encaminhou para Secretaria de Estado do Meio Ambiente, pedido de interdição do aterro da cidade de Vera Cruz. Em 2010, o aterro estava na lista de aterros inadequados divulgada pelo inventário estadual de resíduos sólidos (Costa, 2006). 


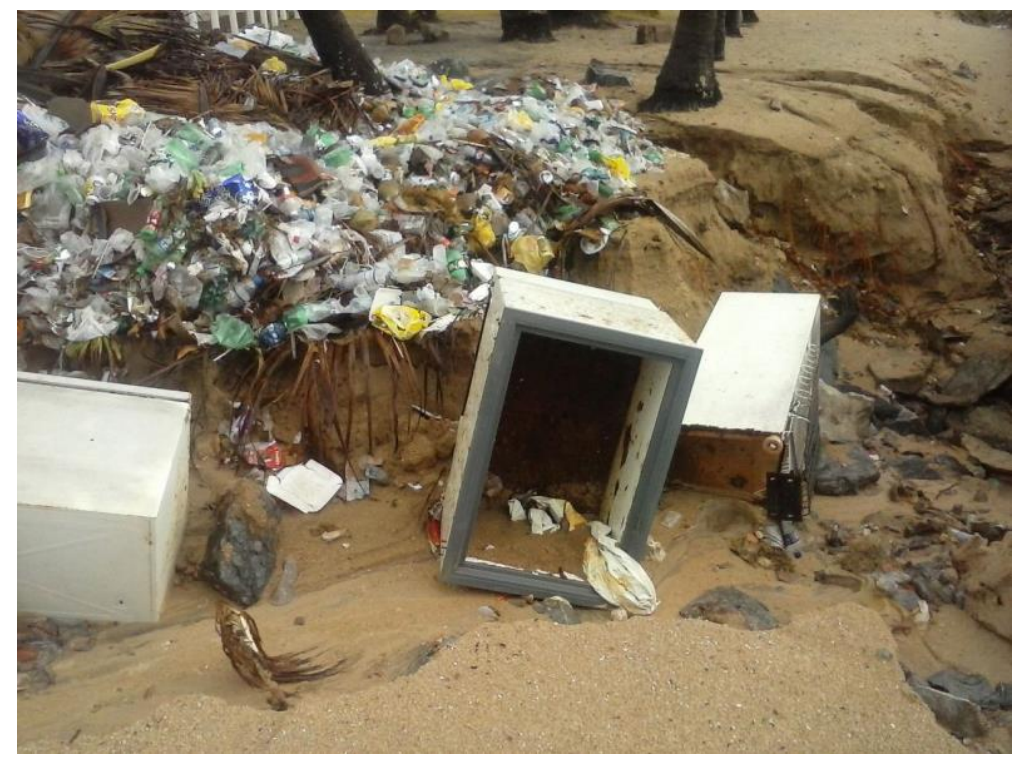

Figura 2: Fotografia do lixo contendo plásticos e entulho em Baiacu. Fonte: Flávio Catão, 2015

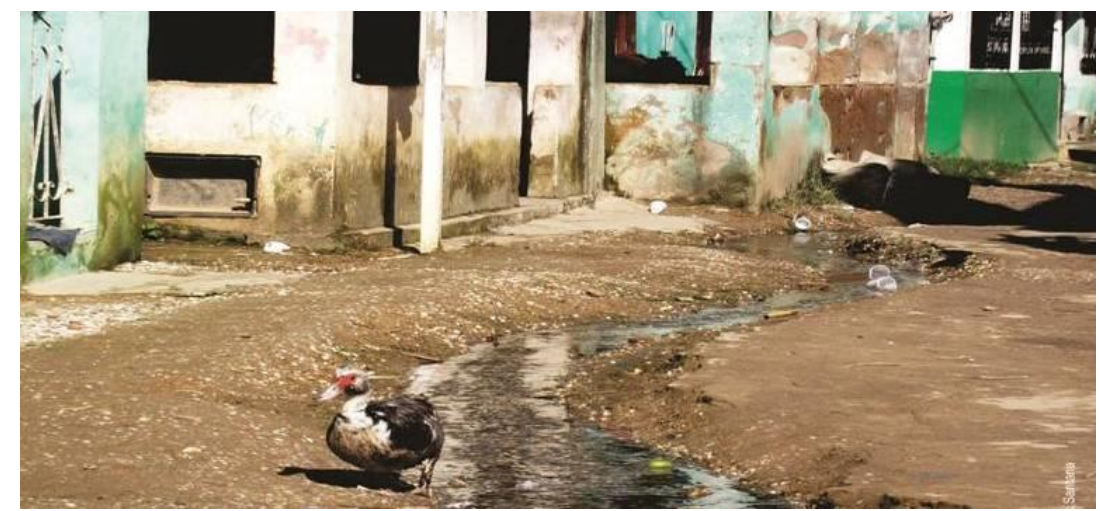

Figura 3: Fotografia de uma região da comunidade de Baiacu.

Fonte: Maria das Graças Meireles; Erick Santana; Alicia Conceição-2015

A Figura 3 retrata um esgoto a céu aberto, que escoa para o mar de Baiacu. Os estudos mostraram também que a maioria das residências não lava o reservatório de água e que suas instalações hidráulicas residenciais apresentam vazamentos e tubulações antigas. Outra realidade observada indica que muitas residências utilizam poços particulares, de origem duvidosa, já que inexiste controle de qualidade nesse tipo de poço. Foi verificada também, a inexistência de um saneamento básico em alguns locais da comunidade, pois os dejetos residenciais acabam se destinando ao esgoto sem tratamento para a maré;

Os resultados mostraram que a turbidez, $\mathrm{pH}$, dureza, sulfeto, cor aparente; nitrato, nitrito e amônia das amostras de águas de consumo em Baiacu e de Cachoeira estão dentro da faixa estabelecida pelos órgãos reguladores. No entanto, as amostras estavam praticamente isentas de cloro e apresentaram a presença de coliformes em $40 \%$ das amostras (Tabela 01). Sabe-se que a água de consumo não deverá conter bactérias indicadoras de contaminação fecal e que a inexistência de cloro pode ocasionar o aparecimento de microorganismos indesejáveis, corroborando com os resultados dos testes microbiológicos obtidos. Assim, isto pode disseminar diversos tipos de doenças nas comunidades, já que o consumo de água de qualidade duvidosa 
pode prejudicar a sobrevivência do ser vivo principalmente nos adolescentes que constituem a parcela da população que inspira preocupação, do ponto de vista toxicológico, por apresentarem maior absorção dos contaminantes do que os adultos, em razão de seus organismos não estarem completamente desenvolvidos (Francis, 2011; Marcelo, 2010).

Tabela 01- Resultados de turbidez, cloro, pH, amônia e coliformes totais das amostras de água potável.

\begin{tabular}{|c|c|c|c|c|c|}
\hline Amostra & $\begin{array}{c}\text { Turbidez } \\
\text { (uT) } \\
\left(\mathrm{mg}^{-1} \mathrm{~L}^{-1}\right)\end{array}$ & $\begin{array}{c}\text { Cloro } \\
\left(\mathrm{mg} \cdot \mathrm{L}^{-1}\right)\end{array}$ & $\mathrm{pH}$ & $\begin{array}{c}\text { Amônia (mg. } \mathrm{L}^{-} \\
1 \text { ) }\end{array}$ & Coliformes Totais \\
\hline $\begin{array}{c}1 \\
2 \\
3 \\
4 \\
5 \\
6 \\
7 \\
8 \\
9 \\
10\end{array}$ & $\begin{array}{c}1,35 \\
1,25 \\
1,0 \\
1,1 \\
0,9 \\
0,89 \\
1,01 \\
1,02 \\
1,01 \\
1,0\end{array}$ & $<0,2$ & $\begin{array}{l}6,6 \\
6,5 \\
6,7 \\
6,9 \\
7,0 \\
7,1 \\
7,3 \\
7,2 \\
6,9 \\
6,5\end{array}$ & $\begin{array}{l}0,0 \\
0,0 \\
0,1 \\
0,1 \\
0,1 \\
0,0 \\
0,1 \\
0,0 \\
0,0 \\
0,0\end{array}$ & $\begin{array}{l}\text { Presente } \\
\text { Ausência } \\
\text { Presente } \\
\text { Ausência } \\
\text { Presente } \\
\text { Ausência } \\
\text { Ausência } \\
\text { Presente } \\
\text { Ausência } \\
\text { Ausência }\end{array}$ \\
\hline VMP* & $5\left(\mathrm{mg} \cdot \mathrm{L}^{-1}\right) \mathrm{uT}$ & $\begin{array}{c}0,2-2 \\
\mathrm{Cl}_{2} \underset{1}{\left(\mathrm{mg} . \mathrm{L}^{-}\right.}\end{array}$ & $6-9,5$ & $\begin{array}{c}1,5\left(\text { como } \mathrm{NH}_{3}\right) \\
\left(\mathrm{mg} \cdot \mathrm{L}^{-1}\right)\end{array}$ & Ausência \\
\hline
\end{tabular}

${ }^{*}$ VMP (Valores máximos permitidos), com base em Ministério da Saúde. Portaria № 2.914, de 12 de dezembro de 2011. Normas de qualidade da água potável.

\section{CONCLUSÃO}

O registro de imagens do lançamento de esgotos no leito do rio, a inadequada distribuição dos resíduos urbanos e industriais e a coleta seletiva ineficazes sinalizaram importantes fontes de contaminação nas cidades de Cachoeira e de Baiacu. As pesquisas de campo também mostraram que em muitos locais, o saneamento básico se encontra inadequado, já que os dejetos são lançados no meio sem tratamento e, consequente chegam ao litoral, poluindo assim, o ambiente.

Os dados revelam que a água consumida em alguns locais, do ponto de vista microbiológico, não está apropriada para o consumo, pois se constatou que a presença de coliformes totais em 40 $\%$ das amostras e que o teor de cloro se encontra abaixo dos valores indicados pelos padrões. Assim sendo, o consumo da água contaminada pode ocasionar doenças, por isso recomenda-se limpeza dos reservatórios residenciais, manutenções nas tubulações periodicamente como também, a necessidade de monitoramento continuo da qualidade da água e a participação intensa dos órgãos públicos nestas ações. Desse modo, pode-se garantir a preservação do meio ambiente e da vida de todos aqueles que transitam nas comunidades de Cachoeira e de Baiacu na Baía de Todos os Santos.

\section{REFERENCIAS BIBLIOGRÁFICAS}

1. APHA/AWWA/WEF. EATON, A.D et al. Standard methods for the examination of water and wastewater. 21a ed. Washington: American Public Health Association. 2005.1082 p. 
2. COSTA, A. B. Caracterização Molecular e Isotópica de Material Orgânico em Sedimentos da Baia de Todos os Santos-Ba. 2006. 124 p. Tese (Doutorado em Geofísica) - Instituto de Geociências. Universidade Federal da Bahia, Salvador. 2006.

3. EMBASA. Relatório anual para informação ao consumidor. Cachoeira, 2011. Disponível em: <http://www.embasa.ba.gov.br/sites/default/files/relatorio_anual/RAIC_2011_Cachoeira_d o_Mato.pdf>. Acesso em: 13. agos. 2014.

4. HATJE , V.; ANDRADE, J. B. Baía de Todos os Santos: Aspectos Oceanográficos. Salvador: EDUFBA. 2009.305 p.

5. FRANCIS. W. Water: Its History, Characteristics, Hygienic and Therapeutic Uses. USA: Editora: Palala Press. 2015. 62 p.

6. LABTAM, MIEB - 2008. Laboratórios de Tecnologias Ambientais Análises Físico-Químicas, Cor, Turbidez, pH, Temperatura, Alcalinidade e Dureza Disponível em: <http://www.biologica.eng.uminho.pt/TAEL/downloads/analises/cor\%20ph\%20t\%20alcalinidade\%20 e\%20dureza.pdf>. Acesso em: 01 fev. 2014.

7. MARCELO, L., Fundamentos de Qualidade e Tratamento de Água. 3a ed. São Paulo: Átomo. 2010. 496 p.

8. RIOS, C. M. Lixo e Cidadania: Um Estudo Sobre Catadores de Recicláveis em Divinópolis - Mg. 2008. 80 f. Dissertação (Mestrado em Educação, Cultura e Organizações Sociais) - Fundação Educacional de Divinópolis. Universidade do Estado de Minas Gerais. 2008.

9. ROSA, L.; ELEUTÉRIO, M.; ALVES, T.; COSTA, A. Diagnóstico da gestão dos resíduos sólidos do município de Cachoeira - BA. Cruz das Almas, 2001. In: I Jornada de Engenharia Sanitária e Ambiental - I JESAM, 2011. 